\title{
Conjunctival Kaposi Sarcoma
}

National Cancer Institute

\section{Source}

National Cancer Institute. Conjunctival Kaposi Sarcoma. NCI Thesaurus. Code C4578.

A Kaposi sarcoma arising from the conjunctiva. 